\title{
TOTAL QUALITY MANAGEMENT AND CONTEMPORARY HOTEL INDUSTRY
}

\author{
Mr Ivica Batinić, Vocational schools, Vukovar, danica.batinic@vu.t-com.hr
}

\begin{abstract}
Strong competition in the market has caused the development of a new management approach known as Total Quality Management (TQM). Due to importance that quality plays in achieving competitive advantage, the hotel industry started to apply TQM. During the introduction of these systems, hotel companies may use different approaches to suit their own buseiness requirements. In doing so, 'TQM standards' can be used, or various international standards and models of business excellence Malcolm Balridge National Quality Award and European Quality Award.
\end{abstract}

Key words-quality, total quality management (TQM), hotel industry, Ritz Carlton

\section{INTRODUCTION}

It is becoming quite evident that the quality has grown, particularly in the last relatively short period of time, from the object of control into strategic goal and competitiveness factor, evolving into one of the most important competitive weapons of business organizations, especially in the global market. Crucial for such a radical quality position and role change were, and still are, circumstances and fierce battles for customers and consumers that demand more and more every day, and expect satisfactory fulfilment of their needs, wishes and even demands. This is actually the need to establish the highest possible values for consumers, which is a framework for quality that should be seen in a much broader context than before.

Acceptance of such an approach will most likely lead the business organization to long-term profitable business and development, which will eventually, alongside to customer satisfaction, mean satisfaction of all other parties (employees, owners, suppliers). In order to achieve this, the right way is the strategic decision to introduce of TQM.

\section{WHAT IS TOTAL QUALITY MANAGEMENT (TQM)?}

Total Quality Management (TQM) is a corporate business management philosophy that accepts the indivisibility of customer needs and business objectives ... It ensures maximum efficiency and effectiveness in business and market leadership by introducing the processes and systems that will promote excellence, prevent the emergence of errors and ensure that every aspect of the business will be focused on customer needs and improving their business goals without increasing or taking useless effort ". 1 Total quality management program is a highly effective program that provides the necessary business tips, tools and techniques to increase the level of customer satisfaction, improved relationships with suppliers and directs the organization to profitable partnerships and helps to identify and eliminate errors ". ${ }^{26}$ Total quality management (TQM) is a concept and a system based on the philosophy that assumes a comprehensive way of enhancing and improving the quality, as well as other performance, which is possible to achieve through research and constant improvement of each process within the organization, where the activities focused in that direction are carried out systematically, integrated and consistent. In this sense, TQM refers not only to management of the quality in a specific way, but also to quality management". "The main goals of the system based on the philosophy of total quality management are to achieve the maximum possible value for consumers, as well as high efficiency and effectiveness to

\footnotetext{
${ }^{1}$ Pike,J.,Bernes,R.: .: “Tqm in action.: “,Chapman\&Hall, London,1994.

${ }^{2}$ Kelly, M. J.: "Upravljanje ukupnom kvalitetom“,

Potecom, Zagreb, 1997

${ }^{3}$ Hunt,V.D.: "Managing for quality "Irvin,Illinois, 1993
} 
organization and producers. This can be achieved by maximizing consumer satisfaction and high levels of productivity and efficiency in business. In order to achieve above mentioned goals, it is necessary that the concept, TQM, operates on the basis of certain principles. These are primarily the following three:

a)The focus in achieving the best possible consumer satisfaction, not only through satisfaction of all their needs, desires, and even demands, but also through the effort to provide the highest possible value, delight and amazement to customers;

b)The requirement for continuous quality improvement. Because of that, TQM integrates fundamental managerial techniques, efforts to be improved and technical means into disciplined process focused on continuous quality improvement.

c)The request for encouraging all employees full involvement and improvement of personal performance and efficiency, as well as the need for coordinated activities and focus of all individual efforts on common goals within the organization, which requires the initiative to start from the head of management and then gradually spread downwards to the bottom of the organization". 4

It is essential for successful implementation and TQM application to create and maintain a culture, which consists of activities, norms, beliefs, approaches, etc., of all the employees. The introduction and application of TQM is a long-term or better say permanent task. TQM is the total integration of the continuous improvement in the overall work and business activity of the entire company.

\section{TOTAL QUALITY MANAGEMENT AND CONTEMPORARY HOTEL INDUSTRY}

The advantages of the TQM introduction in the contemporary hotel industry are confirmed in practice and are manifold:

4 Skoko, H.: Upravljanje kvalitetom, Zagreb, Sinergija ,2000
- No standstills and delays (customer must not wait)

- No errors (customer mustn't tolerate and pay for the mistake of the staff)

- No unnecessary papers (minimum of written communication forms within the hotel)

- Teamwork and team spirit

- Increase in hotel products and service quality

- Increase in customers satisfaction and keeping their loyalty

- Stronger competitiveness and market power of the hotel

- Reduction of costs in hotel business

- Increase in productivity and profitability

- Increase in all employees satisfaction

- Increase in management quality

- Increase in the reputation and value of the hotel

Problems that may arise during the implementation of TQM:

- Top management (often unwilling to accept or to study)

- No need for change (satisfaction with status quo)

- No confidence in the TQM

- No commitment to participate (hard to accept new commitments)

- No further investment (fear of high costs)

- Short-term results required (long-term process)

- Frequent substitutions (constant adjustment required)

Small hotels also have the need and market interest in TQM. Even though TQM was initially developed and implemented in large businesses, the quality benefits are equal both for large and small businesses. However, small companies (small hotels) have their own characteristics which affect TQM system. Starting from the 
basic principles of TQM, which are: to satisfy desires, needs and expectations of customers, consumers, guests; small companies have their own advantages and disadvantages.

Advantages of small businesses (hotels) in introducing TQM are:

- Organization structure is simple which facilitates the introduction of quality system,

- Easier to explain the quality program and gain confidence in the system,

- Every employee is in constant contact with the product and hotel service and guests, and has a clearly defined task and responsibility,

- Employees often do different jobs so they are more interconnected and familiar with the totality of the hotel business,

- Training and education is easier to organize,

- Greater management and employees connection,

- Faster and easier to see the deficiencies and weaknesses

- Faster and easier to detect and satisfy the desires of guests.

Disadvantages of small businesses (hotels) in the introduction of TQM:

- Education is usually lower compared to big hotels;

- Training of employees are rarely organized because for managers they mean the loss of working hours of employees, problems with replacement and expense for owners;

- Small hotel managers and owners often do not have a market vision and strategy so they are reserved when it comes to TQM;

- Small hotel managers and owners expect faster results that TQM cannot provide;

- Due to ignorance, resistance to TQM, all novelties and new ideas is often provided,
- Owner, his knowledge and culture dominate the management of a small hotel and all depends on their TQM understanding;

- No cooperation and understanding of owners and managers makes TQM introduction difficult;

- Small number of employees may cause the appearance of 'bad apples' where only one or two employees may prevent changes (if they're afraid that it means more work and responsibility).

Small hotel owners and managers should decide whether and how important TQM, examine the long-term benefits through greater care for guests. Once introduced, TQM system increases motivation of the staff and work environment by creating and reinforcing our team spirit and teamwork.

Those who expect quick results and effects of TQM make a mistake and they lose in the long term. Those who are aware that market changes and that it is necessary to constantly adjust to it, gain in the long term because TQM provides diagnosis of weaknesses in business and potentiates market power and perspectives. TQM is not a medicine you take once to provide immediate results, it is learning and accepting healthy way of thinking and working entirely oriented toward a fulfilment of the needs, desires and expectations of the customers, the consumers (guests).

\section{TQM IMPLEMENTATION IN HOTEL CHAIN 'RITZ CARLTON' BUSINESS}

"The Ritz-Carlton is a brand of luxury hotels and resorts with 80 properties located in major cities and resorts in 26 countries worldwide.The Ritz-Carlton is the world's first hotel brand to introduce TQM into the hotel business". 5 The introduction of TQM system lasted three years

${ }^{5}$ www.ritzcarlton.com 
and almost all polls show that $97 \%$ of guests are satisfied with the service and products of this chain. Hotel chain Ritz-Carlton explained successful implementation of TQM through three following stages:

\section{Quality awareness development - preparation}

- Develop a strategy of quality

- Define quality policy

- Develop methodology

- Build a support system

- Employees' education, training.

II. Organization of quality

- Set goals for each employee;

- Form teams for quality and development teams;

- Define criteria for quality.

\section{III.Implementation}

- Develop processes and development projects;

- Use assessment methods and feedback;

- Total quality management". 6

Each stage has its own procedure, requires work, patience and persistence. The process of TQM introduction is long lasting (one to two years) and after introducing it needs constant maintenance and development. According to the latest research conducted by hotel chain RitzCarlton, the application of these phases has raised the business in their hotels to the highest level and made the hotel service quality flawless

"The application of TQM system brought the following results:

- Flawless facilities

- Immaculate hotel staff

- Flawless hotel products and services

- All troubles and problems with hotel guests removed

\footnotetext{
${ }^{6}$ business.highbeam.com/
}

- Trust in hotel staff

- Hotel guests safety

- compliance with the terms

- true price and hotel service quality level ratio

- staff errors prevention

- Keeping the guests well informed"?

\section{CONCLUSION}

Today, strong competition and increasing consumer demands made the quality a fundamental factor for survival in the market, profitability and overall development of country's economy and its individual businesses and companies. Quality is the priority and necessity of market competitiveness. Quality is a process that has the ability to shape the future. Approach to quality has evolved from the concept relates to the quality of products and services to the term related to the concept of management. Building a quality system requires long-term and welldesigned application of manager methods optimization and management, with the aim of creating new relationship and behaviour of all employees towards (non) quality and consumer. The best and most effective quality management system is the one built by the hotel company management and whose construction includes all its employees. Construction of the quality system and its implementation brings a lot of benefits to a hotel company. Processes become better, awareness of the quality raises, the motivation and identification of collaborators is greater, a 'premium' is on the horizon, companies are recognized through certification. But there is also a risk, since many of the hotel companies and the society in general, cannot follow such a complex project, and management must be constantly encouraged. Cancelling the rule brings more disappointment and de-motivation than not implementing the quality system at all. Achieved level of quality is often difficult to maintain and continually improve then build and get a quality certificates. By using all available human and material resources, TQM combines all management techniques, existing ones and new 
ways to improve the business and all technical expertise and resources, all focused at the continuous improvement of all processes. Implementation of TQM requires dedication, discipline and sustained effort by all employees, because it includes everyone and it depends on everyone. Each activity needs to function properly and be dedicated to a common goal. TQM is a system that provides a systematic and continuous improvement of all work processes, improved product and services quality, and also the culture of life today and in the future. It avoids useless efforts and resource waste because it achieves the goal in the shortest time and at the lowest cost. TQM system is fully oriented to the market, guided by the customer, the customer is the king in a system of total quality because the process begins with the customer (customer desires) and ends with the customer (satisfied customer). Each participant in the creation of quality is important: every employee decides, works and is responsible for the quality of their task. The concept of TQM is based on respect for the individual and social responsibility, and has a tendency to extend to all activities of individuals and society as a whole.

\section{REFERENCES}

1.Hunt,V.D.: "Managing for quality "Irvin,Illinois, 1993

2.Pike,J.,Bernes,R.: .: “Tqm in action.: ",Chapman\&Hall, London, 1994.

3. Kelly, M. J.: "Upravljanje ukupnom kvalitetom", Potecom, Zagreb, 1997.

4.Skoko, H.: Upravljanje kvalitetom, Zagreb, Sinergija ,2000

WEBPAGES:

$\underline{\text { www.ritzcarlton.com }}$

business.highbeam.com/

corporate.ritzcarlton.com 